\title{
Behavioural Finance and Malaysian Culture
}

\author{
Mohamed Albaity ${ }^{1} \&$ Mahfuz Rahman ${ }^{1}$ \\ ${ }^{1}$ University of Malaya, Malaysia \\ Correspondence: Mohamed Albaity, University of Malaya, Malaysia. E-mail: m_baity@um.edu.my
}

Received: September 9, 2012

Accepted: September 28, $2012 \quad$ Online Published: October 16, 2012

doi:10.5539/ibr.v5n11p65

URL: http://dx.doi.org/10.5539/ibr.v5n11p65

\begin{abstract}
This paper examines how gender, religion, and ethnic differences influence the key determinants of individual investment behavior, which are risk taking, skill, luck, happiness, maximization, regret, confidence and trust. We find that gender difference is significantly associated with risk taking behavior and maximization as well as overconfidence. Religious beliefs and ethnic origins significantly affect life time income risk, regret, maximization, happiness, confidence and trust. However, the addition of these, Malaysian have relatively high level of regret and risk taking propensity in portfolio, and low level of maximization, happiness and general risk taking behavior than non Malaysian.
\end{abstract}

Keywords: behavioral finance, Malaysian culture, trust, overconfidence, religion

\section{Introduction}

Behavioral finance has made advances in explaining the behavior of markets. It focuses on the irrational behavior of the individuals in the economy. Studies found that culture and beliefs influence how individuals make economic decision as well as investment decisions (Hong et al., 2004; Huang, 2008; Chui et al., 2010; Beugelsdijk \& Frijns, 2010; Guiso et al. 2006 and 2008). In the past, the relationship between gender and risk taking behavior has been studied quite frequently. One particular aspect that has received a lot of attention in recent years is the significance of difference in risk taking behavior by gender as a determinant of household investments (Campbell, 2006). For instance, Jianakoplos and Bernasek (1998) investigate how women are different from men in risk aversion. The authors come to the conclusion that women are more risk averse than men. It also indicates that there is a positive relationship between women age and risk aversion. Women hold less risky investment as their age increase than men. Graham, Stendardi, Myers and Graham (2002) found that women are more comprehensive in information processing than men and tend to give more weight to negative information therefore leading them to be more risk averse than men. In addition, it is also well documented that overconfidence bias varies based on gender (Baber \& Odean, 2001; Lundeberg, Fox \& Puncochar, 1994). Men tend to be more overconfident than women, which can be linked to women's risk aversion behavior in general.

However, individual risk taking behavior is also influenced by regret (Inman \& Zeelenberg, 2002; Zeelenberg et al., 1996; Zeelenberg \& Beattie, 1997; Zeelenberg, 1999). For example, people tend to avoid regret of making a bad investment or shame of reporting a loss in the future by avoiding risk now which lead to being risk averse investor. In contrast, if people have more than one option, where one is more risky than the others and there is always feedback on the outcome of the riskier option, this could lead to risk seeking. However, researchers document that investors follow the crowd to avoid the feeling of regret where there is a possibility that their decisions prove to be wrong. Personal trust plays such an important role in financial market even though this concept does not fit in to the current financial theory. There is a significant relationship between trust and risk taking (Luhmann, 1979; Seligmen, 1997). For instance, studies found that perceived risk is inversely related with trust (Siegrest et al., 2000; Sjoberg, 2001; Viklund, 2003; Olsen, 2008). In addition, Guiso et al. (2008) argues that one's trust highly depends on his ethnic origin and religious background indicating the relationship between religion background, ethnic origin and risk taking behavior. In contrast, Alesina, and La Ferrara, (2002) found that there is no significant effect of religious beliefs and ethnic origins on trust. Therefore, it will be interesting to know what relationship exists in Malaysia within its multi racial people along with various religious beliefs. Guiso et al. (2003) and Arrunada (2009) argue that religion has significant influence on the financial choices individuals make. Indeed, in many situation people make investment decision by relying on their luck as well. And they take risk when the situation is more uncertain leading to high outcome. Since some people want to fulfill their desire by the best possible outcome, therefore they love to take risk due to the expectation of higher 
returns. However, higher income does not guarantee happiness or life satisfaction. The past studies provide mixed result regarding the relationship between income and happiness (Easterlin, 2001; Frey \& Stutzer, 2002).

Individual investment puzzle in the economy stems from the fact that most households do not invest their optimal amount of capital despite high returns and significant risk premium. This investment behavior poses a very significant question to us. Traditional finance theory argues that investors' willingness to take financial risks is significantly influenced by investment opportunities and risk aversion (Markowitz, 1995; Sharpe, 1964), similarly, the efficient market hypothesis suggest that market are efficient and it is impossible to beat the market due to information availability to all investors (Fama, 1970). Whereas behavioral finance have introduced several new factors that affect household financial decisions. Mostly prior research focuses on only one determinant or one area at a time in analyzing influential individual characteristics. However, past studies indicate mixed results in establishing the relationship between individual characteristics and households' financial decision may be because behaviors differ from one country to the other depending on culture as mentioned by Guiso et al. (2003). Previous work on this area focus on the differences between males and females, religions, race, as well as marital status. However, most of the studies either done in US or done in a global scale such as Statman (2008) who studied 22 countries including Malaysia and found that overall there is a difference in all the items who studies except Regret. This study is different from previous study in three folds. First, this study focuses on Malaysia. This is interesting because behavior differ from one country to the other depending on culture as mentioned by Guiso et al. (2003). In addition, behaviors of different ethnicities can be generalized to other countries with similar ethnicity. Second, Malaysian population consists of three major ethnicities who have their different cultures and religious affiliations. Third rationale is that Malaysian population if composed of four major religions namely, Islam, Buddhism and Hinduism along with Christianity and other minor groups in different religions. It is clear that this entangled society in ethnicity, culture and religion will yield interesting results that help in understanding their behaviors.

More research is clearly needed. To take a step further, this paper therefore, investigate whether there is any significant difference between male and female in terms of risk taking, skill, luck, Happiness, maximization, regret, and trust. We then examine whether individual from different religion background are significantly different in terms of risk taking, skill, believing in luck, Happiness, maximization, regret, and trust. Moreover, we try to identify whether people from different ethnic origin are significantly different in risk taking, skill, luck, Happiness, maximization, regret and trust. Lastly, the relationship between these variables will be investigated whether results confirm previous results or deviate based on the culture and religion.

Our results suggest that there is a significant difference between male and female in term of maximization and general risk taking. The results indicate that there exist a significant difference between religious affiliations in terms of life time income risk, regret, maximization, and trust. In addition, there is a significant difference in regret between Muslims and Buddhist with Buddhist experiencing a higher level of regrets than Muslims. With regard to maximization the difference is between Buddhist and Muslims as well as Buddhist and Christians with Buddhist scoring the highest mean and Muslims the lowest. Lastly, there is a difference between religious affiliations with regard to trust. Christians seem to be the most trusting flowed by Muslims, Buddhist and finally the least trusting are Hindus. The significant difference however was found between Buddhist with Muslims and Buddhist with Hindus. Chinese exhibit a high level of risk taking followed by Malay and lastly Indian. Indians seem to score the highest mean in maximization, happiness and general risk taking while followed by Chinese in maximization and general risk taking but the opposite with happiness. The study also found that, Malaysians have high risk taking propensity in portfolio than foreign students. Malaysian students score low level of maximization, happiness and general risk while scoring high level of regret than non Malaysian

The remainder of this paper is organized as follows. Section 2 reviews the literature on regret, overconfidence, trust, luck and skill, maximization and Happiness or life satisfaction as well as discusses how observable differences in these attributes may affect investment decision making. Section 3 details the data and methods used in this study. Section 4 provides the results and analysis. Section 5 provides concluding remarks with implication for future research.

\section{Literature Review}

\subsection{Gender and Risk Tolerance}

Using Myers-Briggs Type Indicator to examine the personality type biases and how it correlates with gender biases in creating better client profile Pompian and Longo (2004) administrated questionnaires to 100 investors. They found that many personality types and both genders are disposed to behavioral finance biases. For example in terms of gender, females are one third more risk averse than males. Moreover, the most risk tolerant males 
combined with their personality type should invest $100 \%$ in equity base instruments, while the least risk tolerant females combined with their personality type should invest $100 \%$ in fixed income instruments. Jianakoplos and Bernasek (1998) investigated whether women are different than men in risk aversion. Using survey of consumer finance 1989 they model the relative risk aversion on various variables such as wealth, race, age, education and other variables. Based on the theoretical link that suggest that risk aversion will decrease as the wealth increases it is found in this study that female risk aversion is not negatively related to wealth. They found that women are more risk averse than men leading to lower investment in risky assets than risk free assets.

Previous studies suggested that female are more risk averse and less confident than males, however the reasons behind these difference were not clarified. Graham, Stendardi, Myers and Graham (2002) used selectivity model to explain the gender behavior biases regarding investment. They concluded that women are more comprehensive in information processing than men. Males are found to be efficient in information processing when faced with low complexity task while women were more efficient when dealing with high complexity task. Male were found to follow more holistic process in information processing than women. Women on the other hand follow a more detailed information processing. Focusing more on fund manager than simply testing individuals, Beckerman and Menkhoff (2008) results pointed to the following. Females are less risk averse then males as fund managers, there was no difference between male and female fund managers in term of overconfidence, female fund managers avoid competition, financial expertise reduces gender differences however does not totally eliminate it.

\subsection{Regret}

Regret or anticipated regret is one of the factors that are associated with risk taking in behavioral economics. Regret could lead to either risk aversion or risk seeking. Inman and Zeelenberg (2002), Zeelenberg et al. (1996), Zeelenberg and Beattie (1997) and Zeelenberg (1999) found evidences that support both risk seeking and risk aversion with regret is involved in decision making. The logic of the dual relationship is that people tend to embark in regret minimizing process whenever a decision has to be made. This regret minimizing theory lead people to either become risk averse or risk lover. In the regret minimizing-risk maximizing the relationship is established when the individual are asked to how future regret will influence their current decisions (i.e. how would you feel in the future if you made the wrong decision now?). People tend to shield themselves against future regret by avoiding risk now hence opt for the less risky decision. On the other hand, regret could lead to risk seeking behavior. This would happen if the individual is faced with two options or more where one is more risky than the others and there is always feedback on the outcome of the riskier option. Therefore if an individual faced with two choices where one is riskier than the other opting for the less risky option lead to regret if the riskier option turned out to be better than the less risky option (Larrick \& Boles, 1995; Ritov, 1996). However, the anticipated regret will disappear if there is no feedback on what would have been Boles and Messick (1995) and Ritov and Baron (1995).

\subsection{Overconfidence}

Barber and Odean (2000), Odean (1999) and Barber Odean (2001) found that investors trading too much will experience low returns even after controlling for tax loss selling rebalancing and other variables. They concluded in their paper barber and Odean (2001) that this phenomenon of trading too much and earning low returns can be explains by overconfidence. They claim that overconfident investors tend to overestimate the precision of the information leading them to overestimate their gains which cause them to trade too much and earning lower returns. There is also a link between individualism and overconfidence, which Markus and Kitayama (1991) describe as the tendency of of people in "individualistic cultures to think positively about themselves and focus on their own internal attributes, such as their abilities". Indeed, a large body of psychology literature find that individualistic cultures people, like the United States, believe that their abilities are above average, unlike people in collectivistic cultures, like Japan (Markus \& Kitayama, 1991; Heine et al.,1999). It also suggests that "people in individualistic cultures are likely to be more overconfident about the precision of their information than are people in collectivistic cultures". In addition, Baber and Odean (2001), Lundeberg, Fox and Puncochar (1994) found that there exist gender differences in overconfidence bias. Both men and women exhibit the overconfidence bias by trading excessively however, men tend to be more overconfident than women. Women being less overconfident than men can be linked to their risk aversion behavior in general.

\subsection{Trust}

Luhmann (1979) and Seligmen( 1997) indicated that there is a relationship between trust and risk taking, others argued that trusting is equal to risk taking (Yamagishi, 2000). On the other hand, Luhmann $(1979,1988)$ suggested that risk must exist for trust to occur and when trust occur more risk will be attractive. This indicates 
that there is some kind of loop in the relationship between risk taking and trust. On the relationship between risk and trust, Siegrist (2000), Siegrest et al. (2000), Sjoberg (2001) and Viklund (2003), Olsen (2008) found that perceived risk is negatively related with trust, in other words, the lesser the trust the greater the perceived risk. Research also reveals that there is little or no correlation between one's decision to trust and one's overall level of risk aversion (Ashraf \& Bohnet, 2006; Eckel \& Wilson, 2004). However, according to Guiso et al. (2008) one's trust highly depends on his ethnic and religious background whereas Alesina and La Ferrara, (2002) found that differences in religion and ethnic origin do not significantly influence on the level of trust in most economically developed countries.

\subsection{Luck and Skill}

Zuckerman (1979) and Miller and Ross (1975) Fiske and Taylor (1991), Baumeister (1998), Duval and Silvia (2002) found that people tend to attribute success to their own skills and failures to bad luck. Blaine and Crocker (1993) found that individuals with high self-esteem believe they are lucky and tend to exaggerate their control over events, especially successful events. Camerer and Lovallo (1999) reported lower level of luck when skill is not accounted for. On the other hand, Armor and Taylor (2002) indicate that greater uncertainty can induce greater optimism such that people become risk taker. Certainly, the inclusion of a skill component might increases risk taking. Put differently, if skill does not help in success, luck can ignite optimistic beliefs.

\subsection{Maximization}

Schwartz et al (2002) using Simon's (1957) concept of satisficer which is the mixture between satisfy and suffice studied the relations between maximization, regret, happiness, life satisfaction, and optimism among other variables. Using questionnaires they found that maximization was negatively related with happiness, optimism, self esteem and life satisfaction. On the other hand, maximization was positively related to depression, perfectionism and regret. Maximizers desire the best possible outcome while satisficer desire the outcome that is good enough. The result suggested that maximizes tend to regret more, look for perfection in their decision and depressed while they are less happy than satisficer, not very optimistic and have low level of self esteem and life satisfaction. This could be because maximizers are demanding investors and risk lover which lead them to expect higher returns on their investments.

\subsection{Happiness or Life Satisfaction}

Easterlin (1974) indicated that there was a positive relationship between happiness and individual income in the US. Easterlin (1995), Blanchflower and Oswald (2004) Frey and Stutzer (2002a), Graham and Pettinato (2002) and Layard (2005) found similar pattern in different countries such as France, the UK, Germany, Italy, Netherlands and Japan in different periods of time. Many studies have been done on the quality of life or life satisfaction however they tackle issues as goals, depression, personality and health. Few researches have used data connecting happiness and financial satisfaction such as Michalos (1991), Michalos and Orlando (2006) and Van Praag et al (2010). Although the relationship found between income and happiness was positive Easterlin (2001) and Frey and Stutzer (2002) indicated that there is no clear cut negative or positive relationship. Argyle (1999) in his book mentioned that higher income is associated with greater happiness, although the relation between income and happiness is stronger in relatively low-income countries than in relatively high-income countries such as the United States which was on average constant between 1942 and 1991 according to Antonio Falato (2008). Happiness seems to increase with income up to a certain point, but not beyond it. Isen and Patrick (1983) found that as the person become happier his reaction toward risk becomes lower.

\section{Data and Methodology}

The aim of this study is to investigate whether there is a significant difference in gender, religious affiliations, ethnicity and the country of origin with regard to risk taking propensity, regret, maximization, happiness trust and general risk taking. Previous studies on investor's behavior have largely utilized questionnaire survey for data collection. Considering that the study is interested in behavior and the first reactions that emerge when a scenario is presented a questionnaire survey is implemented as the method of data collection. The questions were adopted from Statman (2008) with the addition of only one question about general risk. Following Statman (2008) the questionnaire was distributed to Malaysian undergraduate students with business and finance majors in two public universities in Malaysia. The questionnaire was self administrated and collected immediately to capture the first thought and answers of the individual students. The total number of questionnaires distributed is 750 and the total number of usable questionnaire is 609 .

\section{Results and Analysis}

This section reports the results that answer the questions of the study. Table 1 below the mean standard 
deviation, minimum and maximum of the variables measured. For the risk in income (portfolio) question, the result is to indicate that if the respondent is willing to take a risk in his/her lifetime income (portfolio) how much will that be compared to a guaranteed $50 \%$ gain with the current income (portfolio). The mean of lifetime income risk is a little higher at 11.32 this indicate that on average Malaysian are willing to risk their lifetime income only if the upside is five times larger than 11.32. On the other hand, the risk on portfolio on average is higher at 12.41 though the two questions are phrased in the same manner. Statman (2008) explained that could happen because investors tend to think of their money in layers where portfolio income is in a higher layer than job income. Standard deviation of both risk questions are 7.64 for income risk and 7.15 for portfolio risk. In addition, Malaysian seems to have high propensity of regret at 6.8 and maximization at 6.52 similar to the finding of Statman (2008). High level of happiness is found among Malaysians at almost 6.8 while in terms of trust they were lower at 4.43. Lastly the general level of risk taking for Malaysian investors seems to be modest at 5.23. The standard deviations indicate that there is variability in the responses ranging between 1.87 and 2.41 .

Table 1. Descriptive statistics

\begin{tabular}{lll}
\hline Variables & Mean & Std. Deviation \\
\hline Risk in income & 11.32 & 7.64 \\
Risk in portfolio & 12.41 & 7.15 \\
Luck & 3.89 & 2.21 \\
Overconfidence & 5.78 & 1.88 \\
Regret & 6.77 & 2.03 \\
Maximize & 6.52 & 2.41 \\
Happiness & 6.77 & 1.89 \\
Trust & 4.43 & 2.21 \\
Risk & 5.23 & 1.87 \\
\hline
\end{tabular}

Table 2 repots the demographic of the respondents. Majority of the respondents were female, $78 \%$ were Muslims and $76.3 \%$ were Malay. The second highest religion is Buddhism at $17 \%$ followed by Christianity at 2.6 and lastly Hinduism at 2. In terms of race, the second highest is Chinese at $20.6 \%$ and followed by Indians and others at $3.1 \%$.

Table 2. Demographic profile of the respondents

\begin{tabular}{llll}
\hline & & Frequency & Percentage \\
\hline Sex & Female & 439 & $72 \%$ \\
& Male & 170 & $28 \%$ \\
\hline \multirow{2}{*}{ Religion } & Islam & 475 & $78 \%$ \\
& Buddhism & 105 & $17 \%$ \\
& Christianity & 17 & $2.6 \%$ \\
& Hinduism\& Others & 12 & $2 \%$ \\
\hline \multirow{2}{*}{ Race } & Malay & 465 & $76.3 \%$ \\
& Chinese & 126 & $20.6 \%$ \\
& Indian \& Others & 18 & $3.1 \%$ \\
\hline
\end{tabular}

Table 3 tests the difference between male and female in term of risk taking, regret, maximization, happiness, trust and general level of risk taking. The results suggest that there is a significant difference between male and female in term of maximization and general risk taking. Men score higher than females in all the aspects except the general level of risk taking where women seem to be a higher risk taker than men.

Results about differences in religious affiliations for all the questions are reported in table 4 . The results indicate that there exist a significant difference between religious affiliations in terms of life time income risk, regret, maximization, and trust. The result of life time income risk taking indicates that there is a significant difference between Christens and the other three religious affiliations. The highest income risk taking investors are Christens while the least are the Buddhists may be because their level of regrets is high as prior studies have documented that there is a both negative and positive significant relationship between risk taking behavior and regret. Our results indicate that the level of regret is high in Buddhism compare to Christianity signifying least risk tolerance in income. It represents negative relationship between risk tolerance in income and regret.

In addition, there is a significant difference in regret between Muslims and Buddhist with Buddhist experiencing 
a higher level of regrets than Muslims. With regard to maximization the difference is between Buddhist and Muslims as well as Buddhist and Christians with Buddhist scoring the highest mean and Muslims the lowest. Lastly, there is a difference between religious affiliations with regard to trust. Christians seem to be the most trusting flowed by Muslims, Buddhist and finally the least trusting are Hindus. The significant difference however was found between Buddhist with Muslims and Buddhist with Hindus.

Table 3. Differences between men and women

\begin{tabular}{lllll}
\hline Variables & Male Mean & Female Mean & Mean Difference t-test & t-value \\
\hline Risk tolerance in income & 11.79 & 11.14 & -.643 & -.706 \\
Risk tolerance in portfolio & 12.73 & 12.28 & -.453 & -.532 \\
Luck & 3.35 & 4.10 & $0.756^{*}$ & 2.90 \\
Overconfidence & 6.15 & 5.64 & $-0.514^{*}$ & 2.31 \\
Regret & 6.96 & 6.70 & -0.261 & -1.077 \\
Maximization & 7.20 & 6.26 & $-0.946^{*}$ & -3.342 \\
Happiness & 6.72 & 6.78 & 0.057 & 0.255 \\
Trust & 4.36 & 4.46 & 0.107 & 0.368 \\
Risk & 4.96 & 5.34 & $0.378^{* *}$ & 1.699 \\
\hline
\end{tabular}

Note: $*$ and $* * *$ significant at $1 \%$ and $10 \%$ respectively.

Table 4. Differences between religious affiliation

\begin{tabular}{|c|c|c|c|c|}
\hline Variables & Religion & Mean & Difference between groups & F-test difference for race \\
\hline \multirow[t]{4}{*}{ Risk tolerance in income } & Islam & 11.35 & & 0.583 \\
\hline & Christianity & 14.33 & & \\
\hline & Buddhism & 10.73 & & \\
\hline & Hinduism & 11.14 & & \\
\hline \multirow[t]{4}{*}{ Risk tolerance in portfolio } & Islam & 12.28 & Christian with & 2.830 \\
\hline & Christianity & 19.00 & Muslim** & \\
\hline & Buddhism & 12.25 & Buddhist** & \\
\hline & Hinduism & 10.29 & Hindus $* * *$ & \\
\hline \multirow[t]{4}{*}{ Luck } & Islam & 3.85 & & 0.22 \\
\hline & Christianity & 4 & & \\
\hline & Buddhism & 4.09 & & \\
\hline & Hinduism & 4.14 & & \\
\hline \multirow[t]{4}{*}{ Overconfidence } & Islam & 5.68 & & 2.11 \\
\hline & Christianity & 6.44 & & \\
\hline & Buddhism & 6.27 & & \\
\hline & Hinduism & 5.43 & & \\
\hline \multirow[t]{4}{*}{ Regret } & Islam & 6.97 & Muslims with & 4.625 \\
\hline & Christianity & 5.89 & Buddhist* & \\
\hline & Buddhism & 5.98 & & \\
\hline & Hinduism & 7.14 & & \\
\hline \multirow[t]{4}{*}{ Maximization } & Islam & 6.78 & Buddhist with & 4.123 \\
\hline & Christianity & 6.51 & Christian** & \\
\hline & Buddhism & 8.33 & Hindus** & \\
\hline & Hinduism & 6.08 & & \\
\hline \multirow[t]{4}{*}{ Happiness } & Islam & 6.81 & & 0.283 \\
\hline & Christianity & 7.00 & & \\
\hline & Buddhism & 6.59 & & \\
\hline & Hinduism & 6.57 & & \\
\hline \multirow[t]{4}{*}{ Trust } & Islam & 6.77 & Muslims with & 2.451 \\
\hline & Christianity & 4.31 & Buddhism*** & \\
\hline & Buddhism & 4.44 & & \\
\hline & Hinduism & 5.12 & & \\
\hline \multirow[t]{4}{*}{ Risk } & Islam & 3.71 & & 0.114 \\
\hline & Christianity & 4.44 & & \\
\hline & Buddhism & 5.24 & & \\
\hline & Hinduism & 4.89 & & \\
\hline
\end{tabular}

Note: $* * *$ and $* * *$ significant at $1 \%, 5 \%$ and $10 \%$ respectively. 
Table 5 reports the results of differences in ethnicity in the same variables. Chinese exhibit a high level of risk taking followed by Malay and lastly Indian. The same trend that investors are willing to gamble more on their portfolio than their life time income emerge here with higher means in favor of risk taking in portfolio for all ethnicities than risk taking in life time income. Indians seem to score the highest mean in maximization, happiness and general risk taking while followed by Chinese in maximization and general risk taking but the opposite with happiness. Malay seems to come second in happiness but third in maximization and general risk taking. Regret and trust are the two variables with significant difference among ethnicities. Indians seems to score the highest level of regret however the statistical difference is between Malay with mean score of 7 and Chinese with mean of almost 6 . In terms of trust Chinese appear to be the most trusting ethnicity followed by Malay and finally Indians. The significant difference is found between Chinese and Malay as well as Chinese and Indians. Previous studies showed that religion influences behavior (e.g. Kumar at al., 2011; Worthington et al., 2003; Wan Ahmad et al., 2008; Hilary \& Hui, 2008).

Table 5. Difference between ethnicities

\begin{tabular}{|c|c|c|c|c|}
\hline Variables & Race & Mean & Difference between groups & F-test difference for race \\
\hline \multirow[t]{3}{*}{ Risk tolerance in portfolio } & Malay & 12.36 & & 0.220 \\
\hline & Chinese & 13.08 & & \\
\hline & Indian & 9.27 & & \\
\hline \multirow[t]{3}{*}{ Risk tolerance in income } & Malay & 11.38 & & 1.389 \\
\hline & Chinese & 11.33 & & \\
\hline & Indian & 9.82 & & \\
\hline \multirow[t]{3}{*}{ Luck } & Malay & 3.83 & & 0.51 \\
\hline & Chinese & 4.13 & & \\
\hline & Indian & 3.91 & & \\
\hline \multirow[t]{3}{*}{ Overconfidence } & Malay & 5.65 & Malay with Chinese & $2.79 * * *$ \\
\hline & Chinese & 6.22 & & \\
\hline & Indian & 6.09 & & \\
\hline \multirow[t]{3}{*}{ Regret } & Malay & 6.99 & Malay with Chinese & $7.793^{*}$ \\
\hline & Chinese & 5.94 & & \\
\hline & Indian & 6.91 & & \\
\hline \multirow[t]{3}{*}{ Maximization } & Malay & 6.77 & & 0.955 \\
\hline & Chinese & 6.52 & & \\
\hline & Indian & 6.38 & & \\
\hline \multirow[t]{3}{*}{ Happiness } & Malay & 7.45 & & 1.146 \\
\hline & Chinese & 6.52 & & \\
\hline & Indian & 6.79 & & \\
\hline \multirow[t]{3}{*}{ Trust } & Malay & 6.57 & Malay with Chinese & $3.67^{*}$ \\
\hline & Chinese & 7.45 & & \\
\hline & Indian & 6.77 & & \\
\hline \multirow[t]{3}{*}{ Risk } & Malay & 4.31 & & 0.562 \\
\hline & Chinese & 5.01 & & \\
\hline & Indian & 3.64 & & \\
\hline
\end{tabular}

Note: $* * *$ and $* * *$ significant at $1 \%, 5 \%$ and $10 \%$ respectively.

Table 6 reports the results of the significant difference between local and foreign students in Malaysia. In terms of lifetime income risk taking propensity foreign students appears to score a higher mean than Malaysian students. On the other hand Malaysian students have high risk taking propensity in portfolio than foreign students. Malaysian students score low level of maximization, happiness and general risk while scoring high level of regret than non Malaysian students. Both local and foreign students score equal level of trust which indicates a lower level of trust. Only in happiness there is a significance difference between Malaysian and non-Malaysian students where non-Malaysian students score the high mean in happiness. 
Table 6. Differences between Malaysians and non-Malaysians

\begin{tabular}{lllll}
\hline Variables & Malaysian Mean & Non-Malaysian Mean & Mean Difference t-test & t-value \\
\hline Risk tolerance in income & 11.32 & 10.91 & 0.414 & 0.409 \\
Risk tolerance in portfolio & 12.41 & 12.55 & -0.137 & -0.142 \\
Luck & 3.89 & 4.08 & -0.184 & 0.622 \\
Overconfidence & 5.78 & 5.98 & -0.202 & 0.801 \\
Regret & 6.77 & 6.61 & 0.165 & 0.598 \\
Maximization & 6.52 & 6.73 & -0.204 & -0.635 \\
Happiness & 6.77 & 7.83 & $-1.068^{*}$ & -4.245 \\
Trust & 4.43 & 4.41 & 0.025 & 0.084 \\
Risk & 5.23 & 5.35 & -0.117 & -0.415 \\
\hline
\end{tabular}

Note: *significant at $1 \%$.

Table 7 reports the correlation coefficients values between the variables. Individuals with high Portfolio Risk propensity tend to have high income risk propensity and are lucky while risk averse in general though very weak. Lucky people seem to be less overconfident, feel less regret, trusting and are not maximizer. Overconfident individuals are less regretful; tend to maximize their outcome and risk averse. Individual who experience regret are maximizers and less trusting. Previous studies documented that investors of individualistic cultures tend to be more overconfident (e.g. Odean, 1998; Gervais \& Odean, 2001; Scheinkman \& Xiong, 2003). Since we know that individualism is weak in East Asian countries, and there is a positive relationship exist between people in individualistic cultures and overconfident, therefore in general we may conclude that East Asian countries, such as Malaysian people are less overconfident, more regretful, maximizers and less trusting compare to individualistic cultures people, like the United States. Lastly, happy people are more trusting than non-happy people.

Table 7. Correlation coefficients

\begin{tabular}{|c|c|c|c|c|c|c|c|c|}
\hline Variables & Income Risk & Portfolio Risk & Luck & Overconfidence & Regret & Maximize & Happy & Trust \\
\hline Risk tolerance in income & 1 & & & & & & & \\
\hline Risk tolerance in portfolio & $0.71^{*}$ & 1 & & & & & & \\
\hline Luck & 0.04 & $0.08^{* * *}$ & 1 & & & & & \\
\hline Overconfidence & 0.04 & 0.01 & $-0.10^{* *}$ & 1 & & & & \\
\hline Regret & 0.00 & 0.02 & $-0.11 * *$ & $0.09 * *$ & 1 & & & \\
\hline Maximization & -0.03 & -0.02 & $-0.1 * * *$ & $0.23^{*}$ & $0.20^{*}$ & 1 & & \\
\hline Happiness & 0.05 & 0.01 & -0.05 & $0.07 *$ & 0.05 & 0.01 & 1 & \\
\hline Trust & 0.04 & 0.04 & $0.09^{* *}$ & 0.04 & $-0.13 *$ & -0.03 & $0.21^{*}$ & 1 \\
\hline Risk & -0.04 & $-0.11 * *$ & 0.07 & $-0.12 * *$ & 0.05 & $-0.11 * *$ & -0.01 & 0.08 \\
\hline
\end{tabular}

\section{Discussion and Conclusion}

The results discussed earlier are mostly consistent with previous studies done on the same variables. Females tend to be luckier, happier, trusting and more risk taker in general terms compared to males while they are also less risk averse with income and portfolio less overconfidence, less regretful, low maximizers than males. The general conclusion for the Malaysian individuals is that males and females differ in luck, overconfidence, maximization and general risk level. Maximization which was addressed by the question "I always want to have the best. Second best is not good enough for me. How much do you agree with this statement?" differed between Malaysian males and females indicating that males tend to maximize their outcome than females. Malaysian females feel luckier than males although both experience low level of luck. Previous researches indicate that male is more overconfidence than females which is what this study concluded. However in term of the general risk, which aims in gauging the riskiness individuals are willing to take in general and not in investment decisions, the findings showed that females consider themselves risk takers. In the risk taking propensity in lifetime income and portfolio Malaysian males are risk lovers more the females. These results are not contradicting since each is focusing in different points of risk.

Religion seems to show differences in the variables tested. Differences were found in terms portfolio risk taking, regret, maximization and trust. Christians scored highest in lifetime income and portfolio risk, overconfidence, and happiness, and they are significantly different from other groups in portfolio risk. Muslims scored the 
highest in trust and they are significantly different from Buddhist in trust and regret. Buddhist scored the highest mean in maximization and general risk level and they are statistically significantly different from the Christian and Hindus mean scores. Hindus scored higher in luck, regret however they were not significantly different in any of them. Religious affiliation reflects cultures and traditions and therefore most of these significant differences can be explained by them. However few studies were done on the same variables and in Malaysia. The results of religious affiliation mentioned regarding regret and trust were confirmed when the respondents were categorized based on their ethnicity. Malays scored highest in lifetime income risk, regret, maximization and happiness and they are significantly different from Chinese in overconfidence, and regret. Chinese scored highest mean in lifetime portfolio risk, luck, overconfidence, trust, and general risk level. A significant difference is found between Chinese and Malay in trust. Therefore, Malays are risk taker, more regretful, maximizer, happier than other races. On the other hand, Chinese are risk taker, luckier, more overconfident, and more trusting and risk taker in general. Indian on the other hand scored the lowest in all variables.

Malaysians are risk taker with income, and more regretful while non-Malaysians are risk takers in portfolio, luckier, more overconfident, maximizer, happier, and risk taker in general. Both Malaysians and non-Malaysians are equal in trust. Malaysian individuals differ from non-Malaysians only in happiness where non-Malaysians are happier than non-Malaysians.

\section{References}

Alesina, A., \& La Ferrara, E. (2002). Who trusts others? Journal of Public Economics, Elsevier, 85(2), 207-234. http://dx.doi.org/10.1016/S0047-2727(01)00084-6

Argyle, M. (1999). Causes and Correlates of Happiness in Well-Being. In Kahneman, D., E. Diener and N. Schwarz (Eds.), The Foundations of Hedonic Psychology (pp. 353-373). New York, NY: Russel Sage Foundation.

Armor, D. A., \& Taylor, S. E. (2002). When predictions fail: The dilemma of unrealistic optimism in Heuristics and Biases. In T. Gilovich, D. Griffin, \& D. Kahneman (Eds.), The Psychology of Intuitive Judgment (pp. 334-347). New York, NY: Cambridge University Press. http://dx.doi.org/10.1017/CBO9780511808098.021

Arruñada, B. (2009). Specialization and Rent-Seeking in Moral Enforcement: The Case of Confession. Journal for the Scientific Study of Religion, 48(3), 443-61. http://dx.doi.org/10.1111/j.1468-5906.2009.01459.x

Ashraf, N., Bohnet, I., \& Piankov, N. (2006). Decomposing trust and trustworthiness. Experimental economics, 9, 193-208. http://dx.doi.org/10.1007/s10683-006-9122-4

Barber, B. M., \& Odean, T. (2000). Trading is hazardous to your wealth: The common stock investment performance of individual investors. The Journal of Finance, 55(2), 773-806. http://dx.doi.org/10.1111/0022-1082.00226

Barber, B. M., \& Odean, T. (2001). Boys Will Be Boys: Gender, Overconfidence, and Common Stock Investment. Quarterly Journal of Economics, 116(1), 261-292. http://dx.doi.org/10.1162/003355301556400

Baumeister, R. F. (1998). The Self. D. T. Gilbert, S. T. Fiske, \& G. Lindzey, (Eds.). New York, NY: McGraw-Hill.

Beckmann, D., \& Menkhoff, L. (2008). Will Women Be Women? Analyzing the Gender Difference among financial experts. KYKLOS, 61(3), 364-384. http://dx.doi.org/10.1111/j.1467-6435.2008.00406.x

Beugelsdijk, S., \& Frijns, B. (2010). A cultural explanation of the foreign bias in international asset allocation. Journal of Banking and Finance, 34, 2121-2131. http://dx.doi.org/10.1016/j.jbankfin.2010.01.020

Blaine, B., \& Crocker, J. (1993). Self-esteem and Self-serving Biases in Reactions to Positive and Negative Events. [An Integrative Review, in Self-esteem: The Puzzle of Low Self-regard, by R. Baumeister] New York, NY: Plenum.

Blanchflower, D., \& Andrew, J. O. (2004). Well-Being over Time in Britain and the USA. Journal of Public Economics, 88(7-8), 359-386.

Boles, T. L., \& Messick, D. M. (1995). Reverse outcome bias: the influence of multiple reference points on the evaluations of outcomes and decisions. Organizational Behavior and Human Decision Processes, 61, 262-275. http://dx.doi.org/10.1006/obhd.1995.1021

Camerer, C., \& Lovallo, D. (1999). Overconfidence and Excess Entry: An Experimental Approach. The American Economic Review, 89(1), 306-318. http://dx.doi.org/10.1257/aer.89.1.306

Chui, A. C. W., Titman, S., \& Wei, K. C. J. (2010). Individualism and Momentum around the World. The 
Journal of Finance, 65(1), 361-392. http://dx.doi.org/10.1111/j.1540-6261.2009.01532.x

Duval, T. S., \& Silvia, P. J. (2002). Self-Awareness, Probability of Improvement, and the Self-serving Bias. Journal of Personality and Social Psychology, 82, 49-61. http://dx.doi.org/10.1037/0022-3514.82.1.49

Easterlin, R. (1974). Does Economic Growth Improve the Human Lot? Some Empirical Evidence in Nations and Households in Economic Growth: Essays in Honour of Moses Abramovitz. P. David and M. Reder, (Eds). New York and London: Academic Press, pp. 98-125.

Easterlin, R. (1995). Will Raising the Incomes of All Increase the Happiness of All? Journal of Economic Behavior and Organization, 27(1), 35-48. http://dx.doi.org/10.1016/0167-2681(95)00003-B

Easterlin, R. (2001). Income and Happiness: Towards a Unified Theory. Economic Journal, 111(473), 465-84. http://dx.doi.org/10.1111/1468-0297.00646

Eckel, C. C., \& Wilson, R. K. (2004). Is trust a risky decision? Journal of Economic Behavior \& Organization, 55, 447-465. http://dx.doi.org/10.1016/j.jebo.2003.11.003

Falato, A. (2009). Happiness Maintenance and Asset Prices. Journal of Economic Dynamics and Control, 33(6), 1247-1262. http://dx.doi.org/10.1016/j.jedc.2008.09.007

Fama, E. (1970). Efficient Capital Markets: A Review of Theory and Empirical Work. Journal of Finance, 25(2), 383-417. http://dx.doi.org/10.2307/2325486

Frey, B., \& Alois, S. (2002). What Can Economists Learn from Happiness Research? Journal of Economic Literature, 40(2), 402-35. http://dx.doi.org/10.1257/002205102320161320

Graham, C., \& Stefano, P. (2001). Happiness and Hardship: Opportunity and Insecurity in New Market Economies. Washington, D.C.: Brookings Institution Press.

Graham, J. F., Stendardi, E. J., Myers, J. K., \& Graham, M. J. (2002). Gender differences in investment strategies: an information processing perspective. International journal of bank marketing, 20(1), 17-26. http://dx.doi.org/10.1108/02652320210415953

Guiso, L., \& Paiella, M. (2003). Risk Aversion, Wealth and Background Risk. Temi di discussione (Economic working papers) 483, Bank of Italy, Economic Research and International Relations Area.

Guiso, L., Sapienza, P., \& Zingales, L. (2006). Does Culture Affect Economic Outcomes? Journal of Economic Perspectives, 20(2), 23-48. http://dx.doi.org/10.1257/jep.20.2.23

Guiso, L., Sapienza, P., \& Zingales, L. (2008). Alfred Marshall Lecture - Social Capital as Good Culture. Journal of the European Economic Association, 6(2-3), 295-320. http://dx.doi.org/10.1162/JEEA.2008.6.2-3.295

Hilary, G., \& Hui, K. W. (2009). Does religion matter in corporate decision making in America? Journal of Financial Economics, 93, 455-473. http://dx.doi.org/10.1016/j.jfineco.2008.10.001

Hong, B. K., Chan, K., \& Ng, A. (2004). Invisibility and return volatility. Journal of Financial Economics, 71, 239-263. http://dx.doi.org/10.1016/S0304-405X(03)00166-1

Huang, P. H. (2008). How do Securities Laws Influence Affect, Happiness, \& Trust? Journal of Business \& Technology Law, 257-308.

Inman, J. J., \& Zeelenberg, M., (2002). Regret repeat versus switch decisions: The attenuation role of decision justifiability. Journal of Consumer Research, 29, 116-128. http://dx.doi.org/10.1086/339925

Isen, A. M., \& Patrick, R. (1983). The effect of positive feelings on risk taking: When the chips are down. Organizational Behavior and Human Decision Processes, 31, 194-202.

Jianakoplos, N., \& Bernasek, A. (1998). Are women more risk averse? Economic inquiry, 36, 620-630. http://dx.doi.org/10.1111/j.1465-7295.1998.tb01740.x

Kumar, A., Page, J. K., \& Spalt, O. G. (2011). Religious Beliefs, Gambling Attitudes, and Financial Market Outcomes. (Forthcoming). EFA 2009 Bergen Meetings Paper. Journal of Financial Economics (JFE). Available at http://ssrn.com/abstract $=1335855$

Larrick, R. P., \& Boles, T. L. (1995). Avoiding regret in decisions with feedback: A negotiation example. Organizational Behavior and Human Decision Processes, 63, 87-97. http://dx.doi.org/10.1006/obhd.1995.1064

Luhmann, N. (1979). Trust and power. Chichester, UK: John Wiley \& sons. 
Luhmann, N. (1988). Familiarity, confidence, trust:Problems and al- ternatives in Trust. In D. Gambetta (Ed.), Making and Breaking Cooperative Relations (pp. 94-108). Oxford: Basil Blackwell.

Lundeberg, M. A., Paul W. F., \& Judith, P. (1992). Highly Confident but Wrong, Gender Differences and Similarities in Confidence Judgments. Journal of Educational Psychology, 86(1), 114-121. http://dx.doi.org/10.1037/0022-0663.86.1.114

Michalos, A. C. (1991). Global Report on Student Well-Being: Volume 1, Life Satisfaction and Happiness. Springer-Verlag, New York.

Michalos, A. C., \& Orlando, J. A. (2006). A note on student quality of life. Social Indicators Research, 79(1), 51-59. http://dx.doi.org/10.1007/s11205-005-2404-y

Miller, D., \& Ross, M. (1975). Self-serving Biases in the Attribution of Causality: Fact or Fiction? Psychological Bulletin, 82, 213-225. http://dx.doi.org/10.1037/h0076486

Odean, T. (1999). Do investors trade too much? American economic review, 89(5), 1279-1298. http://dx.doi.org/10.1257/aer.89.5.1279

Olsen, R. A. (2008). Trust as risk and the foundation of investment value. The Journal of Socio-Economics, 37, 2189-2200. http://dx.doi.org/10.1016/j.socec.2008.04.009

Ritov, I. (1996). Probability of regret: anticipation of uncertainty resolution in choice. Organizational Behavior and Human Decision Processes, 66, 228-236. http://dx.doi.org/10.1006/obhd.1996.0051

Ritov, I., \& Baron, J. (1995). Outcome knowledge, regret, and omission bias. Organizational Behavior and Human Decision Processes, 64, 119-127. http://dx.doi.org/10.1006/obhd.1995.1094

Schwartz, B., Ward, A., Monterosso, J., Lyubomirsky, S., White, K., \& Lehman, D. R. (2002). Maximizing versus satisficing: Happiness is a matter of choice. Personality and Social Psychology, 83, 1178-1197. http://dx.doi.org/10.1037/0022-3514.83.5.1178

Seligman, A. B. (1997). The Problem of Trust. Princeton, NJ: Princeton University press.

Siegrist, M. (2000). The influence of trust and perceptions of risks and benefits on acceptance of gene technology. Risk analysis, 20(2), 195-203. http://dx.doi.org/10.1111/0272-4332.202020

Siegrist, M., \& Cvetkovich, G. (2000). Salient Value Similarity, Social Trust, and Risk/Benefit Perception. Risk Analysis, 20(3). http://dx.doi.org/10.1111/0272-4332.203034

Siegrist, M., Cvetkovich, G., \& Roth, C. (2000). Salient value similarity, social trust, and risk/ benefit perception. Risk Analysis, 20, 353-362. http://dx.doi.org/10.1111/0272-4332.203034

Simon, H. A. (1955). Behavioral model of rational choice. Quarterly journal of economics, 59, 99-118. http://dx.doi.org/10.2307/1884852

Sjoberg, L. (2001). Limits of knowledge and the limited importance of trust. Risk Analysis, 21(1), 189-198. http://dx.doi.org/10.1111/0272-4332.211101

Statman, M. (2008). Countries and culture in behavioral finance. CFA Institute Conference Proceedings Quarterly, 25(3). http://dx.doi.org/10.2469/cp.v25.n3.6

Van Praag, B. M. S., Romanov, D., \& Carbonellc, A. F. (2010). Happiness and financial satisfaction in Israel: Effects of religiosity, ethnicity, and war. Journal of Economic Psychology, 31(1), 1008-1020. http://dx.doi.org/10.1016/j.joep.2010.08.008

Viklund, M. (2003). Trust and risk perception in Western Europe: a cross-national study. Risk analysis, 23(4), 727-738. http://dx.doi.org/10.1111/1539-6924.00351

Wan Ahmad, W. M., Rahman, A. A., Ali, N. A., \& Seman, A. C. (2008). Religiosity and Banking Selection Criteria among Malays in Lembah Klang. Shariah J., 16(2), 79-84.

Worthington, E. L., Wade, N. G., Hight, T. L., McCullough, M. E., Berry, J. T., . . . Lynn, O. (2003). The religious commitment inventory-10: development, refinement and validation of a brief scale for research and counseling. Journal of Counseling Psychology, 50, 84-96. http://dx.doi.org/10.1037/0022-0167.50.1.84

Yamagishi, T. (2000). Session on Trust at the 27th International Congress of Psychology. Stockholm, Sweden, July 23-28, 2000.

Zeelenberg, M. (1999). Anticipated regret, expected feedback and behavioral decision-making. Journal of Behavioral 
http://dx.doi.org/10.1002/(SICI)1099-0771(199906)12:2<93::AID-BDM311>3.0.CO;2-S

Zeelenberg, M., \& Beattie, J. (1997). Consequences of regret aversion 2: Additional evidence for effects of feedback on decision making. Organizational Behavior and Human Decision Processes, 67, 63-78. http://dx.doi.org/10.1006/obhd.1997.2730

Zeelenberg, M., Beattie, J., van der Pligt, J., \& de Vries, N. K. (1996). Consequences of regret aversion: Effects of expected feedback on risky decision making. Organizational Behavior and Human Decision Processes, 65, 148-158. http://dx.doi.org/10.1006/obhd.1996.0013

Zeelenberg, M., van Dijk, W. W., van der Pligt, J., Manstead, A. S. R., van Empelen, P., \& Reinderman, D. (1998). Emotional reactions to the outcomes of decisions: The role of counterfactual thought in the experience of regret. Organizational Behavior and Human Decision Processes, 75, 117-141. http://dx.doi.org/10.1006/obhd.1998.2784

Zuckerman, M. (1979). Attribution of success and failure revisited, or: The motivational bias is alive and well in attribution theory. Journal of http://dx.doi.org/10.1111/j.1467-6494.1979.tb00202.x 